\title{
ÁREAS DA REGIÃO LAGUNAR CANANÉIA-IGUAPE SUSCETÍVEIS DE EXPLORAÇÃO PESQUEIRA SEGUNDO DIVERSOS TIPOS DE TECNOLOGIA. I - Pesca com Cerco Fixo
}

\author{
EDUARDO B. RAMOS, JAQUES GALLO e VICENTE M.A. VERRONE \\ Instituto Oceanográfico da U.S.P., S. Paulo, SP, Brasil
}

\section{SYNOPSIS}

With the purpose of obtaining data which could be useful for complementing investigations on estuarine biological oceanography, the authors carried out a survey on the distribution and volume of catch produced by fish-traps used by traditional fishermen in the lagoon region of Cananéia-Iguape (São Paulo, Brasil), mainly for catching mullet. As many as 170 fish-traps were initially spotted and mapped in the whole region, some of which are concentrated in particular areas that seem to be points of more frequent passage of mullet and other fishes, according to the experience and observations of regional fishermen. In consequence of the dam recently built on the Valo Grande - an artificial canal cohich formerly linked the RibeiraRiver to the lagoon system of Cananéia-Iguape - it is expected that the sea-water circulation within the lagoon will be intensified, with a consequent increase in the salinity rates of its waters, which in turn will probably affect the ecological balance of : zme. The authors suggest that a continuous monitoring of the volume and composition of the commercial catch produced by the fish-traps ope ating in the lagoon-region could eventually offer useful data for detecting the alterations of distribution of the several different fish species th.zt are found in the lagoon, in consequence of the foreseen changes in the salinity rates of its waters.

\section{Intrưiução}

Durante o mês de maio de cada ano, no início do inverno austral, grandes cardumes de tainhas (Mugil sp) saem da Lagoa dos Patos (Rio Grande do Sul) e realizam uma migração ao longo da costa sul brasileira, em direção ao norte. Esse deslocamento anual da tainha foi comprovado por Sadowski \& Almeida Dias (em preparo), com auxílio de peixes marcados por ocasião da "corrida".

Esse movimento migratório é bem conhecido de todos os pescadores da região, que dele se aproveitam para capturar grandes quantidades desses peixes com auxílio de diversos tipos de aparelhos, tanto na própria desembocadura da Lagoa dos Patos como em todo o trecho mais ao norte, geralmente em baías, estuários e lagunas,

Os aparelhos geralmente utilizados nessa pesca, ao longo da costa, se constituem de redes de diversos tipos e também, já no Estado de São Paulo, na regiấo lagunar de Cananéia-Iguape, de armadilhas fixas denominadas popularmente de "cercos fixos" ("cercadas" ou "currais" em outras partes do país) cuja concepção e funcionamento são muito semelhantes a aparelhos de pesca de mesmo gênero encontrados em outras partes do mundo. Um estudo sobre a composição da captura produzida por um cerco fixo experimental já foi apresentado por Radasewsky (1976).

Constitui objetivo do presente trabalho, partindo de dados colhidos sobre a localização de cercos fixos existentes na região lagunar e das respectivas produções de alguns deles, extrair informações que possam ser de interesse para complementar estudos de oceanografia biológica estuarina.

\section{O complexo estuarino-lagunar Cananéia-Iguape}

$\mathrm{A}$ área do complexo lagunar estende-se entre as altitudes (S) de $24^{\circ} 41^{\prime}$ (Barra do Icapara) e $25^{\circ} 15^{\prime}$ (Barra do Ararapira), e entre as longitudes (W) de $47^{\circ} 26^{\prime}$ e $\left.48^{\circ}\right)$ )', nos mesmos pontos. Clima - Tropical úmido, com estação invernal bastante nítida; Precipitação anual - Pode alcançar $2.000 \mathrm{~mm}$ em Cananéia, e $1.700 \mathrm{~mm}$ em Iguape. Estação mais chuvosa: - verão; Temperatura do ar - (Cananéia) - Média $21.0^{\circ} \mathrm{C}$; Min. $6.8^{\circ}$; Máx. $38.8^{\circ} \mathrm{C}$.

A região lagunar apresentá duas barras principais, permanentemente abertas, sendo que a barra norte, perto de Iguape (Barra do Icapara), é muito assoreada, permitindo a passagem apenas a pequenas embarcações em condiçōes excepcionais de bom tempo, enquanto que a barra sul (Barra de Cananéia), possibilita o livre tráfego de barcos de até 30 tons. de deslocamento, em condições de bom tempo. Assim sendo esse sistema lagunar sofre uma influência marinha constante, dependendo sua intensidade das condiçōes oceanográficas vigentes na região. A essa influência marinha se contrapõem as descargas dos diversos rios que desembocam no sistema lagunar, sendo que o Rio Ribeira, cuja vazão oscila entre 160 a $1.300 \mathrm{~m}^{3} / \mathrm{s}$ (Brasconsult, 1966), exa o principal curso d'água que mais influia sobre o teor de salinidade de boa parte das águas lagunares, até princípios de agosto deste ano quando seu canal de escoamento artificial - denominado Valo Grande - foi interrompido por uma barragem, obrigando o rio a voltar à sus desembocadura original, mais ao norte, pela Barra do Ribeira.
Essa interrupçao orusca de uma parte ponderável dos afluxos de água doce que o complexo estuarino vinha recebendo há mais de um século, antes do recente barramento do Valo Grande, deverá provocar, ao que tudo indica, sensíveis alterações no mecanismo de penetração da onda de maré pela Barra do Icapara (Fig. 1), com provável elevação das taxas de salinidade do Mar Pequeno, e consequente deslocamento dos pontos de concentracão dos cardumes de Mugilídeos, assinalados por Besnard (1950, p. 5).

\section{Localizaçāo dos cercos fixos no complexo estuarino-lagunar}

Em toda a região lagunar, e particularmente em Cananéia, o principal apareho de captura de tainha e de outros peixes é o cerco fixo, que é encontrado distribuído em diversos pontos da laguna, em áreas preferencialmente escolhidas pelos pescadores, depois de muitos anos de experiências e observações acumuladas dos seus antecessores, e onde eles procuraram conciliar os fatores seguintes:

a) condições batimétricas adequada (o local não pode ser nem fundo nem raso demais);

b) natureza e textura do fundo (deve ser de lama, suficientemente compacta para oferecer embasamento sólido ao cerco ou prejudica seu funcionamento e durabilidade);

c) força e direção apropriadas das correntes de maré (uma força excessiva de corrente impede a instalação do cerco ou prejudica seu funcionamento e durabilidade);

d) ponto de passagem de cardumes (é, obviamente, a condição principal para um bom rendimento do cerco).

Outros fatores secundários podem ainda influir na escolha do "ponto", tais como: 1) maior ou menor facilidade de acesso (distância dos locais de venda); 2) regulamentos restritivos assegurando o desimpedimento dos canais de navegação e acesso à entrada dos rios ou "canais de maré" ("esteiros" ou "gamboas"), etc. Não são esses, entretanto, obstáculos que impeçam inteiramente a instalação de cercos em pontos piscosos. Dentro dos limites pesquisados foram localizados 170 cercos da região lagunar.

Pelo levantamento preliminar efetuado, verifica-se a existência, na referida região lagunar (Mapas 1 e 2), de áreas de concentração de cercos fixos, parecendo o fato demonstrar que essa maior aglomeração de armadilhas em determinados trechos da laguna constitui um indício seguro da passagem freqüente de cardumes por essas áreas, funcionando portanto os cercos como pontos de amostragem continua das populações de peixes que passam por esses locais.

\section{Montagem e operação dos cercos fixos}

$\mathrm{Na}$ construção do cerco entram dois elementos básicos: os "mourões", vara de madeira roliça e tosca que servem de arcabouço à armadilha, e a "palha", amplas esteiras feitas de hastes de taquara (Philostatis aurea), ligadas entre si com auxílio de tranças de arames gaivanizado, mantendo um espaçamento regular ("malha") entre as hastes de cerca de $4 \mathrm{~cm}$ (para os cercos de 
inverno), e de $3 \mathrm{~cm}$ (para os cercos de verão), atuando a "palha" como uma parede para aprisionar os peixes (Fig. 2).

A seletividade do cerco é relativa, uma vez que tem-se observado freqüentemente que peixes pequenos ou de formas achatadas, que thes permitiriam passar facilmente pelas "malhas" do cerco, nele permanecem, só tentando fugir quando o pescador se aproxima com a rede de despesca. Devido à pouco durabilidade da taquara dentro d'água, que geralmente apodrece num período de 3 a 4 meses, e devido à circunstância de que a tainha e os peixes de inverno em geral, apresentam formais mais espessas do que os peixes de verão, principalmente a carapeba (Diapterus rhombus), - pescador se vê obrigado a reconstruir o seu cerco, com grande esforço e despesas, duas vezes por ano, a primeira vez em abril-maio, com malha de $4 \mathrm{~cm}$, para a époça da migração da tainha, e a segunda em setembro-outubro, com malha de $3 \mathrm{~cm}$, para os peixes de verão (Fig. 3). Alguns pescadores, por conveniência ou dificuldades econômicas, só instalam e operam cercos de inverno, para a "safra" da tainha, que é a mais rendosa, tanto em volume quanto em valor médio.

\section{Composição das capturas de diferentes cercos}

Conforme pudemos verificar pelos dados de produção disponiveis (anotações pessoais de pescadores e notas de venda do pescado), referentes a alguns cercos localizados em diferentes pontos da regiāo lagunar (Mapa 1), se a tainha predomina amplamente na pesca de inverno (Radasewsky, 1976), na pesca de verão aparece uma variedade de outras,espécies, algumas das quais se distribuem aparentemente de maneira peculiar, predominando nas capturas de certos cercos e permanecendo ausentes em outros. Se, a título de exemplo, compararmos a composição e o volume da captura dos cercos n.o 2 e 3 (Mapa 1), dentro do período de 15-12-1977 a 14-01-78, durante o qual o número de despescas dos referidos cercos foi igual para ambos, e em dias quase coincidentes, verificamos o seguinte:

\section{Cerco n.o 2 (Rio Baguaçú) - 5 despescas}

\section{Especies}

Tainha e Virote (Mugil sp)

Carapeba (Diapterus rhombeus)

27,5

Robalão (Centropomus undecimalis)

Robalo (Centropomus parallelus)

Cerco n.o 3 (Rio Barbosa) - 5 despescas

Saguá (Boridia grossidens)

Tainha e Virote (Mugil sp)

Paratí (Mugil sp)

Parú (Pomacanthus arcuatus)

Bagre (Genidens genidens)

Caranha (Lutjanus griseus)

Robalo (Centropomus parallelus)

O exame da produção do cerco n.o 3 , ainda que fora do período considerado acima, demonstrou que o mesmo capturou uma maior variedade de espécies do que o cerco n.o 2, sendo que algumas delas, tais como o Saguá e o Parú, parecem ter preferência pela área onde se localiza o referido cerco, enquanto que a carapeba, a qual muito raramente aparece nas capturas do cêrco n 03 , e de outras armädilhas da mesma área, está presente constantemente nas capturas do cerco n.o 2, conquanto ambos os cêrcos tenham aproximadamente a mesma malha. Este último detalhe nos permite eliminar a dúvida de ter ocorrido, na presente comparação, algum efeito devido à seletividade, mesmo moderada, própria de cada cerco.
Por outro lado, no cerco n.o 4, nas proximidades da saida da Barra de Cananéia, são muito feqülentes, além das capturas habituais de tainha, paratí e robalo, as ocorrências de corvina, bagre, linguado e sargo-de-dentes, além do aparecimento ocasional de espécies tipicamente costeiras tais como o espada (Trichiurus lepturus) e galo (Selene vomer), conforme tem sido também observado pelo biologista Ruy de Almeida Dias (comunicação pessoal), em cerco de estudos localizado na mesma área e pertencente ao Instituto de Pesca, da Coordenadoria de Pesquisa de Recursos Naturais da Secretaria da Agricultura e Abastecimento do Estado de São Paulo.

\section{Captura de tainha em três cercos diferentes}

Tomando-se o cerco n.o 1 como ponto de referência, os cercos n.2 e 4 distam de aproximadamente 4,5 e $5,5 \mathrm{~km}$, respectivamente (Mapa 1), havendo portanto uma distância de $10 \mathrm{~km}$ entre o cerco n.o 2 e o n.o 4.

A comparação da produção de tainha dos três cercos referidos, no período de maio a julho de 1977 (Fig. 4) pōe em relevo uma curiosa simultaneidade de capturas nas trếs armadilhas, uma vez que o gráfico individual de cada cerco acompanha bastante fielmente as elevações ou decrescimos da produção dos outros dois.

Sabem os pescadores que a tainha entra no cerco "quando vem o rebojo", isto é, por ocasião da passagem de frentes frias pela região. Assim sendo procuramos verificar se, durante o período considerado e antes dos dias das maiores capturas, ocorreram efetivamente quaisquer perturbações frontais ao sul da área. Pelo exame das Cartas de Pressão à Superfície (D.H.N., 1977) constatamos que, realmente, no período mais acentuado da captura - entre os dias 10 e 24 de junho houve a passagem de três frentes frias pelo trecho de costa entre o Cabo de Santa Marta e Cabo Frio (Åreas "Bravo" e "Charlie"). Essas frentes, entretanto, se fizeram notar na região de Cananéia apenas sob a forma de chuvas fracas (menos de $9 \mathrm{~mm}$ ) de pouca duração, nos dias $15,17 \mathrm{e}$ 22 de junho, sem que se constatassem alteraçōes significativas da temperatura da água lagunar (valor médio $22,0^{\circ} \mathrm{C}$ ), a não ser no dia 10 , quando foram registrados apenas $20,4^{\circ} \mathrm{C}$, na Base de Pesquisas do Instituto Oceanográfico da USP, que se situa a menos de $500 \mathrm{~m}$ do cerco n.o 1. Essa única ocorrếncia é apresentada apenas para registro, uma vez que só com um número maior de observações será possível tirar conclusões sobre esse fenômeno.

Os dados colhidos até o presente sobre a distribuição espacial dos cercos na região lagunar, bem como sobre as outras questōes e aspectos assinalados neste trabalho, não nos permitem, evidentemente, apresentar conclusões, que só poderão ser alcançadas com o prosseguimento e ampliação das pesquisas, até cobrir toda a área do complexo lagunar, a fim de observar possíveis alterações nas populaçōes de peixes que frequentam a laguna, em decorrência das modificações hidrológicas que o fechamento do Valo Grande poderá eventualmente produzir no ambiente lagunar.

\section{Agradecimentos}

Agradecimentos especiais são devidos ao $\mathrm{Sr}$. Geraldo A. Gregório, pela sua prestimosa colaboração em facilitar-nos dados sobre a produção comercial de diversos cercos. A todos os pescadores de Cananéia que nos ofereceram auxílio e valiosas informações, nossa sincera gratidão. Somos particularmentè gratos ao Dr. Ruy de Almeida Dias, do Instituto de Pesca, pelas suas atenções e troca de dados referentes a cerco sob seu controle. Ao velho amigo e experimentado "cerqueiro", St. Francisco O. Pereira, muito agradecemos as indicaçōes recebidas. Aos Srs. Waddington de C. Dotti e Wilson S. Macedo Jr. os melhores agradecimentos dos autores pela incansável colaboração na confecção dos desenhos e gráficos. 


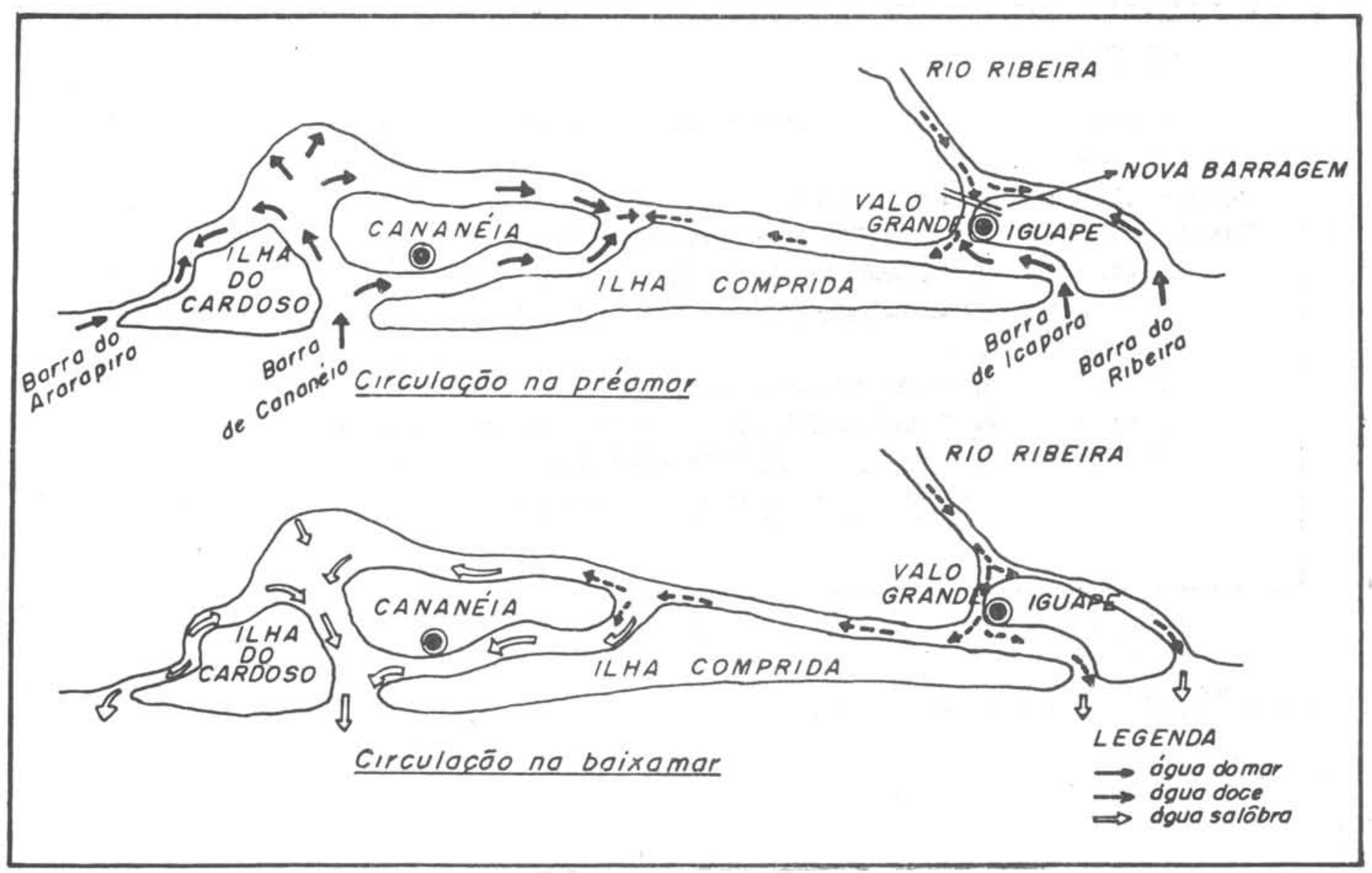

Fig. 1 - Esquema simplificado da influência da onda de maré e do Rio Ribeira sobre as águas do complexo lagunar - antes do fechamento do Valo Grande (segundo Wakamatsu, 1975, adaptado de Miniussi, 1959).

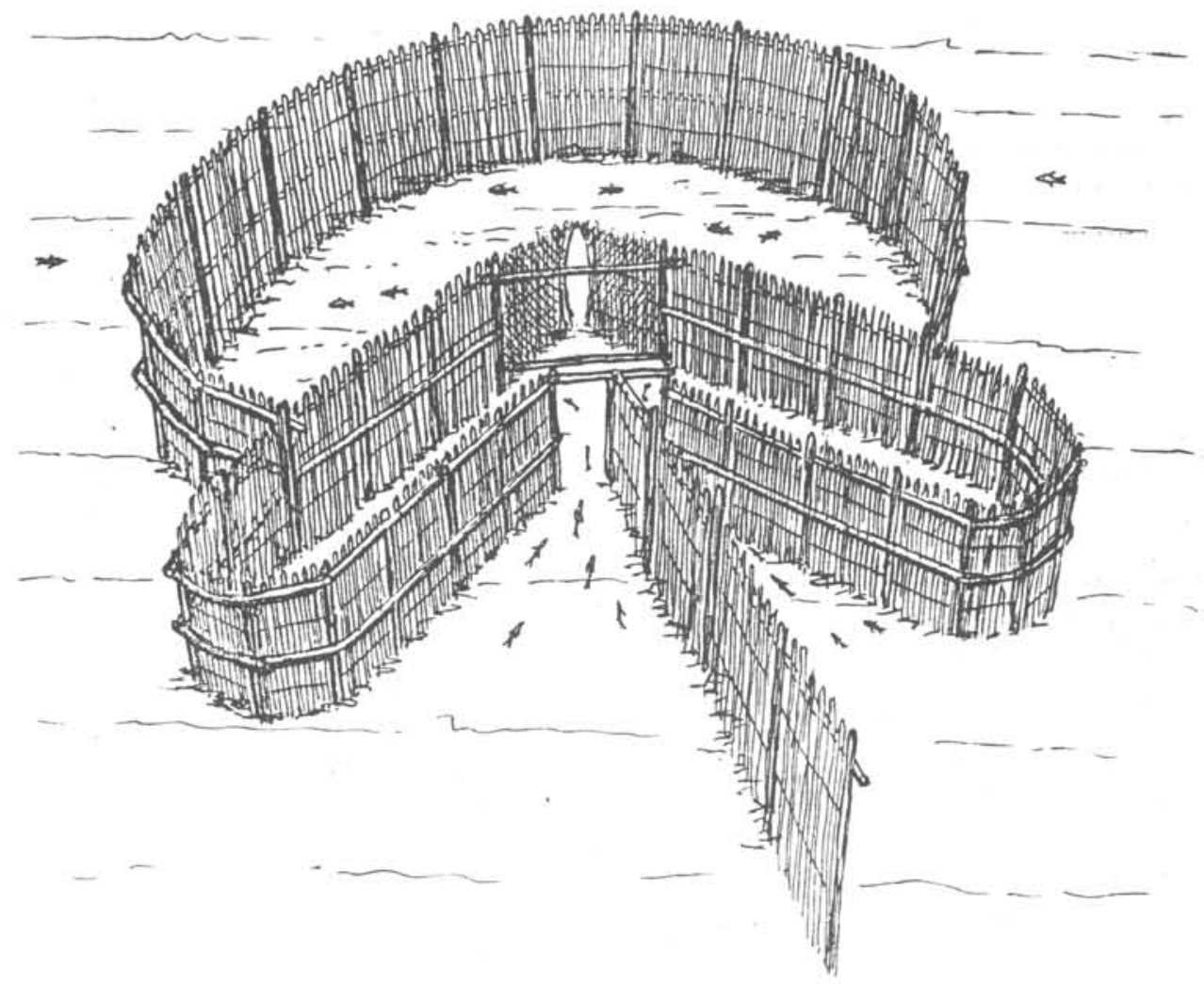

Fig. 2 - Cerco fixo. 


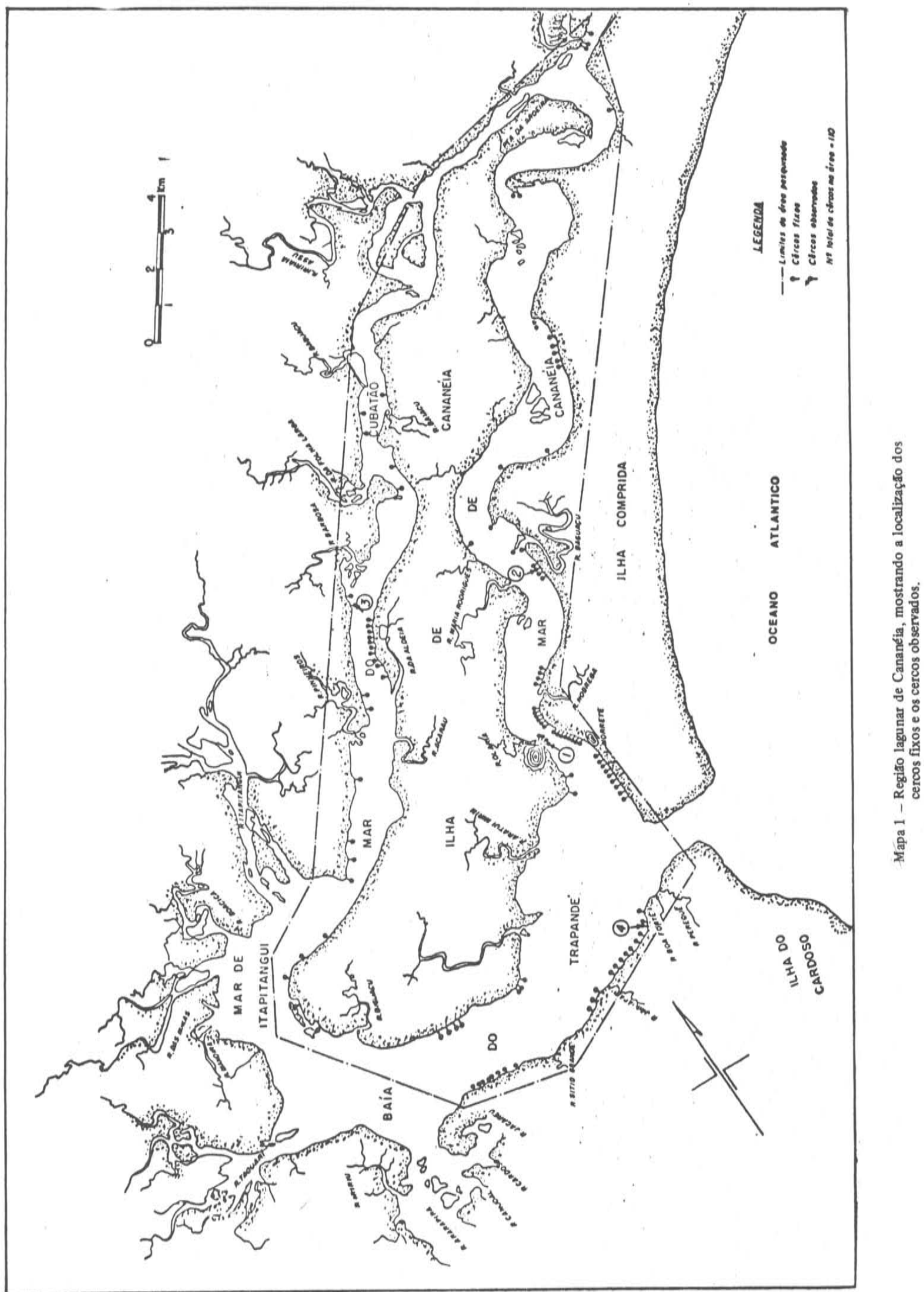




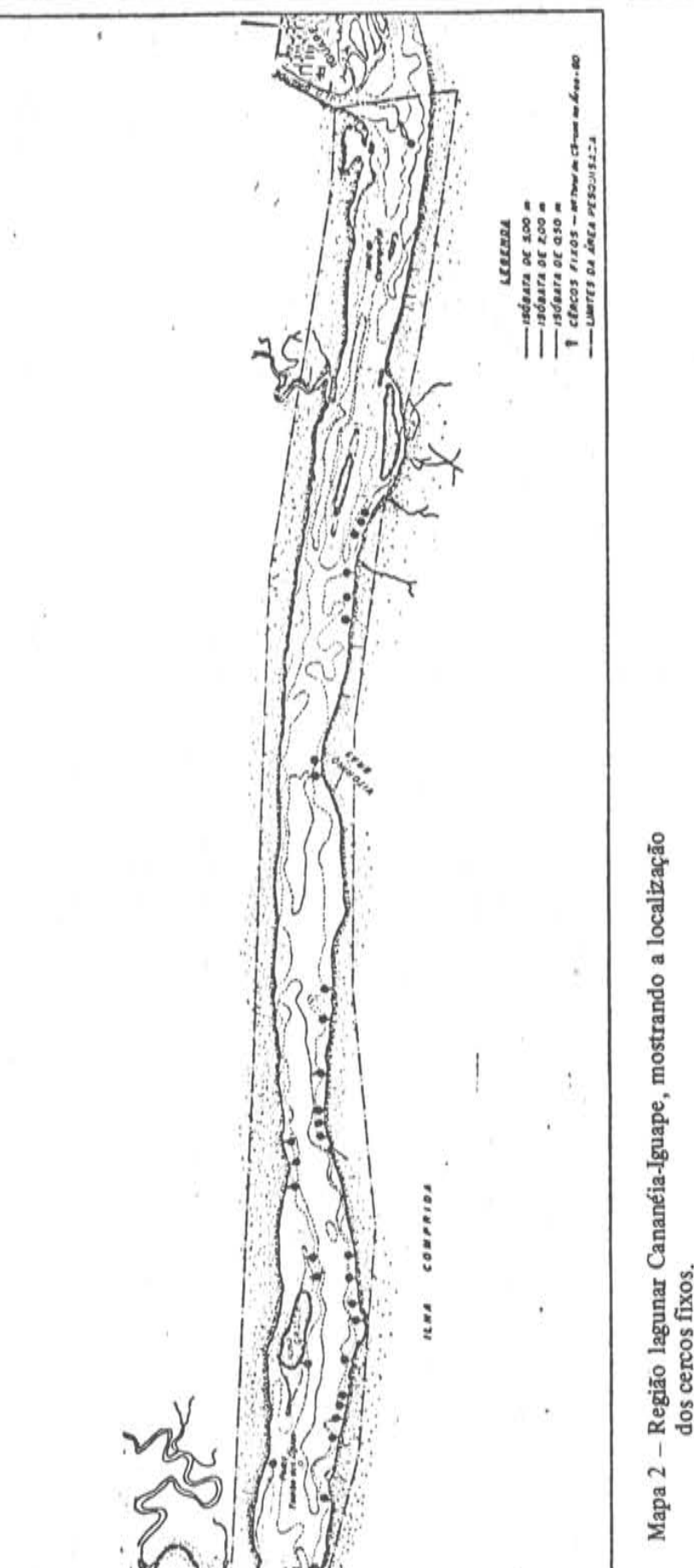




\section{Bibliografia}

BESNARD, W. 1950. Considerações gerais em tôrno da região lagunar de Cananéia-Iguape. II. Diversos aspectos atuais da região lagunar. Bolm Inst. paul. Oceanogr., 1(2): 3-28.

BRASCONSULT, SĀO PAULO. 1966. Plano de Desenvolvimento do Vale do Ribeira e litoral sul. São Paulo, Departamento de Águas e Energia Elétrica - Superintendência do Vale do Ribeira, vol. 5.
D.H.N. 1977. Cartas de pressão à superfície. Rio de Janeiro, Ministério da Marinha - Serviço de Previsão do Atlântico Sul.

MINIUSSI, I.C. 1959. Propagação da onda de maré em tômo da Itha de Cananéia. Contorções Inst. Oceanogr. Univ. S. Paulo, sér. Oceanogr. fís., (2): 1-8.

RADASEWSKY, A. 1976. Consideraçōes sobre a captura de peixes por um cerco fixo em Cananéia, São Paulo, Brasil. Bolm Inst. Oceanogr., S. Paulo, 25(1): 1-28.

WAKAMATSU, T. 1975. A ostra de Cananéia e seu cultivo. São Paulo, SUDELPA/IOUSP, 141 p. 